\title{
Case study on total electron content enhancements at low latitudes during low geomagnetic activities before the storms
}

\author{
Libo Liu, Weixing Wan, Man-Lian Zhang, and Biqiang Zhao \\ Institute of Geology and Geophysics, Chinese Academy of Sciences, Beijing 100029, China \\ Received: 11 December 2007 - Revised: 28 February 2008 - Accepted: 7 March 2008 - Published: 13 May 2008
}

\begin{abstract}
Sometimes the ionospheric total electron content (TEC) is significantly enhanced during low geomagnetic activities before storms. In this article, we investigate the characteristics of those interesting TEC enhancements using regional and global TEC data. We analyzed the low-latitude TEC enhancement events that occurred around longitude $120^{\circ} \mathrm{E}$ on 10 February 2004, 21 January 2004, and 4 March 2001, respectively. The TEC data are derived from regional Global Positioning System (GPS) observations in the Asia/Australia sector as well as global ionospheric maps (GIMs) produced by Jet Propulsion Laboratory (JPL). Strong enhancements under low geomagnetic activity before the storms are simultaneously presented at low latitudes in the Asia/Australia sector in regional TEC and JPL GIMs. These TEC enhancements are shown to be regional events with longitudinal and latitudinal extent. The regions of TEC enhancements during these events are confined at narrow longitude ranges around longitude $120^{\circ} \mathrm{E}$. The latitudinal belts of maxima of enhancements locate around the northern and southern equatorial ionization anomaly (EIA) crests, which are consistent with those low-latitude events presented by Liu et al. (2008). During the 4 March 2001 event, the total plasma density $N_{i}$ observed by the Defense Meteorological Satellite Program (DMSP) spacecraft F13 at $840 \mathrm{~km}$ altitude are of considerably higher values on 4 March than on the previous day in the TEC enhanced regions. Some TEC enhancement events are possibly due to contributions from auroral/magnetospheric origins; while there are also quasiperiodic enhancement events not related to geomagnetic activity and associated probably with planetary wave type oscillations (e.g. the 6 January 1998 event). Further investigation is warrented to identify/separate contributions from possible sources.
\end{abstract}

Keywords. Ionosphere (Equatorial ionosphere; Ionosphereatmosphere interactions; Ionospheric disturbances)

Correspondence to: Libo Liu

(liul@mail.iggcas.ac.cn)

\section{Introduction}

It is well known that, during geomagnetic storms, large and global dramatic disturbances occur in the geospace due to enhanced dissipation of energy of solar winds and/or interplanetary magnetic fields, driving the magnetosphere, thermosphere and ionosphere system deviated considerably from their normal levels. In particular, the considerably perturbed behavior of the ionosphere is commonly known as an ionospheric storm, manifesting as huge increases and/or depletions in total electron content (TEC), electron concentrations and peak height $(h m \mathrm{~F} 2)$ of the F2 layer. Since its discovery, the ionospheric storm has received extensive studies (e.g. Araujo-Pradere et al., 2004; Buonsanto, 1999; Kane, 1973; Kutiev and Muhtarov, 2001; Lin et al., 2005; Liu et al., 2004). As a result, many excellent reviews on this topic have been published (e.g. Buonsanto, 1999; Danilov, 2001; Fejer, 2002; Mendillo, 2006; Prölss, 1995), although many open questions are still unresolved.

Furthermore, even at quiet geomagnetic activity levels, the ionosphere still presents a highly day-to-day variability (e.g. Fejer, 2002; Forbes et al., 2000; Laštovička and Šauli, 1999; Xiong et al., 2006). Some have sources associated with geomagnetic activities, while others possibly have sources in the atmosphere or from below (e.g. Blagoveshchensky et al., 2006; Laštovička and Šauli, 1999; Mikhailov et al., 2004, 2007a). The effects of atmospheric waves on the ionosphere were reviewed by Laštovička (2006). Recently, Mikhailov et al. (2004, 2007b) analyzed the morphology of both positive and negative quiet-time F2-layer disturbances (Q-disturbances). They found that daytime positive and negative Q-disturbances are due to different formation mechanisms. Moreover, Kutiev et al. $(2006,2007)$ reported that the TEC enhancements occurred outside of the initial and main phases of geomagnetic storms. They speculated that these enhancement structures are produced mainly by disturbance dynamo electric fields, and built up after the main phase of the storms; some events appearing at the end of

Published by Copernicus Publications on behalf of the European Geosciences Union. 
prolonged low geomagnetic activity periods can be linked directly to penetrating interplanetary electric field in the equatorial ionosphere.

There is an intriguing feature among the day-to-day variabilities in the ionosphere; that is, compared to the corresponding background level, in some cases electron density is greatly enhanced with an amplitude comparable to the F2layer storm effects for some hours, even up to a day, prior to the onset of geomagnetic storm disturbances. This peculiar feature is termed as the prestorm enhancement by Burešová and Laštovička (2007) or a positive phase before the beginning of a geomagnetic storm by Danilov (2001) and Kane (1973). Danilov (2001) listed it as one of the unsolved problems. Typical examples of these unusual enhancements in the maximum electron density $(\mathrm{Nm} \mathrm{F} 2)$ or the critical frequency $(f o \mathrm{~F} 2)$ of the F2 layer can be found in Kane (1973, 2005), Blagoveshchensky et al. (2006), Burešová and Laštovička (2007), Danilov (2001) and Liu et al. (2008). Early works also reported such anomalies, but unfortunately it attracted little attention and has been studied much less than the stormtime behaviors of the F2 region. As a result, we are still lacking information on the characteristics of this phenomenon; the sources and mechanisms responsible for its happening are also unknown.

Burešová and Laštovička (2007) proposed that these enhancements might be a sub-group of such Q-disturbances. Therefore, studying these unusual enhancements in the ionosphere will improve our understanding on the physical processes during ionospheric storms and the day-to-day variability of the ionosphere. It also has potential applications in the ionospheric weather.

Recently, Burešová and Laštovička (2007) reported the occurrence of $N m \mathrm{~F} 2$ prestorm enhancements at European middle latitudes. They found that about $20-25 \%$ of strong storms are accompanied by strong prestorm enhancements. Later, Liu et al. (2008) investigated the 21 April 2001, 29 May 2003, 22 September 2001, 9 August 2000, and 10 May 2002 events at low latitudes in the Asia/Australia sector. All five events they reported illustrate that $N m \mathrm{~F} 2$ and TEC were simultaneously enhanced significantly at equatorial ionization (EIA) crest latitudes. Both Burešová and Laštovička (2007) and Liu et al. (2008) demonstrated that the solar flare effects are generally not the main drivers for these enhancements, because the main features of these enhancements do not coincide with the solar flare effects. Moreover, Burešová and Laštovička (2008) found that the E-region appears to be insensitive to prestorm enhancements. Liu et al. (2008) suggested that the plasma vertical drift or zonal electric field is a likely cause for the low-latitude prestorm enhancements, supported by the existence of stronger EIA and the latitudinal coverage of the enhancements during these low-latitude events.

Up to now, we do not know whether or not the signature of the enhancement can be detected in one region when it appears in another region. In other words, it is still not clear whether this kind of unusual enhancements is a regional or global phenomenon. Both Liu et al. (2008) and Burešová and Laštovička (2007) did not provide us with a detailed picture of the spatial coverage of the enhancement events. These enhancements may have a longitudinal dependence. Evidence can be found from a typical example on 28 October 2003. On that day, a large enhancement in foF2 was presented at middle latitudes over Europe (Burešová and Laštovička, 2007), but it was not detected at low latitudes in the Asia/Australia sector. Moreover, it is necessary to determine whether the sources are associated with geomagnetic activity or have their origins in the atmosphere or from below. A detailed comparison of the evolutions of the ionosphere and solar wind and interplanetary parameters is helpful for identifying possible sources. This question has been answered in part by Kutiev et al. $(2006,2007)$. They reported that, although these events are observed during periods of low geomagnetic activity, some cases are attributed to the post-storm effects of preceding storms; while in other cases enhancements appear during prolonged periods of low geomagnetic activity, not connected with the recovery phase of a storm.

The present work collects the regional and global TEC data from global positioning system (GPS) measurements to further investigate this enhancement phenomenon at low latitudes in the Asia/Australia sector. The global GPS TEC data are provided from the global ionospheric maps (GIMs) produced by Jet Propulsion Laboratory (JPL), which make it possible to determine the longitudinal and latitudinal extent of the enhancement events. A regional GPS (the network of International GNSS Service (IGS), formerly the International GPS Service, augmented with GPS receivers from a network located in China) will provide accurately the evolution of TEC at around longitude $120^{\circ} \mathrm{E}$. We will focus on determining the latitudinal and longitudinal coverage of these TEC enhancements in selected cases; and to explore whether or not it can be found in the topside ionosphere using observations of the Defense Meteorological Satellite Program (DMSP) spacecraft. Moreover, on the basis of our observations we will also discuss the possible sources of enhancements.

\section{Data source}

In this work, we still concentrate on selected events rather than statistical analysis. We will present the TEC enhancement events that occurred on 10 February 2004, 21 January 2004, and 4 March 2001, respectively, at low latitudes in the Asia/Australia sector. We select these three events with prolonged low geomagnetic activity on some previous days and preceding a geomagnetic storm. The regional ionospheric total electron content (TEC) is derived from IGS network GPS receivers augmented with a network of GPS receivers located in China along longitude $120^{\circ} \mathrm{E}$ in the Asia/Australia sector. 


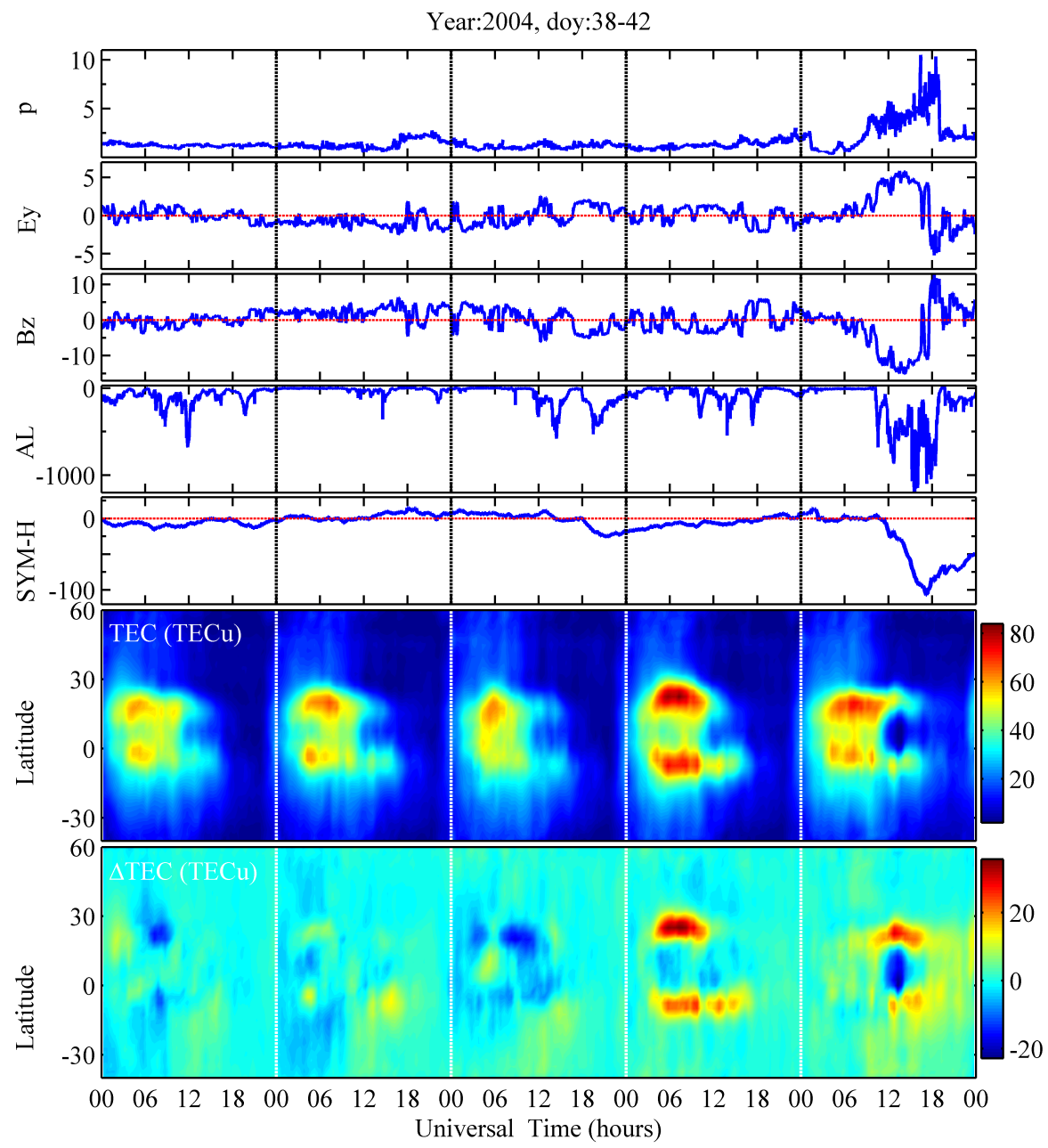

Fig. 1. Solar wind pressure $(p)$, IEF $E_{y}$, and IMF $B_{z}$ measured by the ACE satellite, AL and SYM-H indices, and total electron content (TEC) measured along $120^{\circ}$ E longitude and the deviations ( $\triangle$ TEC) from the median TEC values on 7-11 February (days 38-42) 2004. The median values are evaluated from the 31-day observations centered on 10 February, 2004. The ionospheric TEC were enhanced at low latitudes in both hemispheres on 10 February 2004.

At the same time, GIMs for ionospheric TEC have been routinely produced at JPL since 1998 using GPS data collected from the IGS worldwide GPS network (e.g. Mannucci et al., 1998; Iijima et al., 1999). A GIM provides a snapshot of TEC for a universal time interval, and such maps are produced continuously through a day. A version of GIMs with temporal resolution of $2 \mathrm{~h}$ is archived at the website $\mathrm{ftp} / / /$ cddisa.gsfc.nasa.gov/gps/products/ionex/. In terms of the snapshots of TEC as a function of longitude (in degrees), latitude (in degrees) and universal time (UT in hours), we can determine the longitudinal and latitudinal structure of the ionospheric signature during these events.

\section{Results}

\subsection{The 10 February (day 41) 2004 event}

The first enhancement event which we considered occurred on 10 February 2004, following by a storm on 11 February 2004. We present in Fig. 1 solar wind dynamic pressure $(p)$, the dawn-dusk component of interplanetary electric field (IEF $E_{y}$ ), the north-south component of interplanetary magnetic field (IMF $B_{z}$ ), as well as AL and SYM-H indices on 711 February 2004. The $p$ and IMF $B_{z}$ parameters are taken from the ACE satellite observations at L1 $\left(\sim 1.42 \times 10^{6} \mathrm{~km}\right.$ from the Earth), while IEF $E_{y}$ is derived from solar wind velocity and IMF measurements by the ACE satellite. Possibly a time delay of $1 \mathrm{~h}$ should be realized due to the propagation time from the $\mathrm{L} 1$ point to the interested altitude of the Earth's ionosphere. Similar to Kutiev et al. (2007), in the 


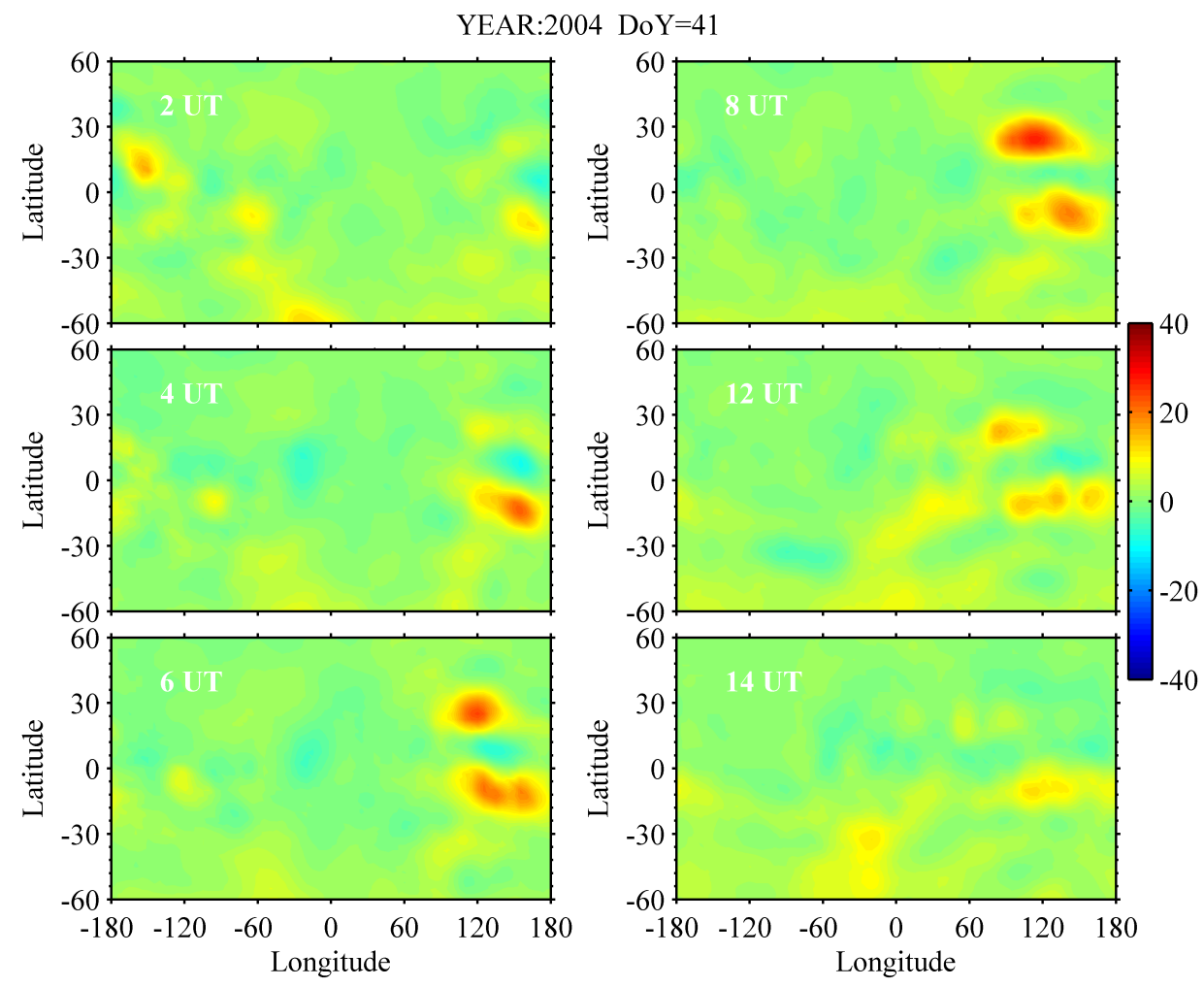

Fig. 2. The deviations ( $\triangle$ TEC) from the median values of JPL GIM total electron content (TEC) as a function of longitude and latitude at six universal times on 10 February (day 41), 2004. The median values are evaluated from the 31-day observations centered on 10 February 2004.

following figures no time-shift correction was made in $p$, IEF $E_{y}$, and IMF $B_{z}$ to account for the propagation time. SYM$\mathrm{H}$ (Iyemori and Rao, 1996) has a time resolution of $1 \mathrm{~min}$, essentially a higher-resolution version of $D_{s t}$. A remarkable feature in Fig. 1 is the onset of a storm on 7-11 February 2004. The preceding days (7-9 February) were geomagnetically quiet, except for a weak depression in the SYM-H index on 9 February with minimum values not exceeding $-27 \mathrm{nT}$. This disturbance is too small to be regarded as a storm, according to the magnetic storm classification. However, as indicated by the AL index, weak to moderate bursts, which are possibly related to substorms, are documented at high latitudes due to the IMF $B_{z}$ southward turnings.

The bottom two panels in Fig. 1 show the regional TEC values and the corresponding deviations $\triangle \mathrm{TEC}$ along $120^{\circ} \mathrm{E}$ during 7-11 February 2004. Here $\Delta \mathrm{TEC}=\left(\mathrm{TEC}-\mathrm{TEC}_{m}\right)$ are the absolute deviations of TEC from the median values $\mathrm{TEC}_{m}$, which are evaluated from the 31-day observations centered on 10 February 2004. The TEC enhancements are described in terms of the deviations of TEC $(\triangle T E C)$ from the reference level. As seen from the TEC contour, the equatorial ionization anomaly (EIA) is well developed and intensified at local noon on 10 February 2004. Two humps appear in the TEC maps. The $\triangle$ TEC is augmented at latitudes of the north and south EIA crests, with maximum positive val- ues larger than $30 \mathrm{TECu}$ (TEC unit, in $10^{16}$ electrons $/ \mathrm{m}^{2}$ ). The main feature of this enhancement event is quite similar to those reported in Liu et al. (2008). After the shock wave and southward IMF $B_{z}$ approaching the Earth, the 11 February 2004 storm started, accompanied by huge disturbances in the ionosphere.

In order to determine the latitudinal and longitudinal coverage of the TEC enhancement, deviations ( $\triangle T E C)$ from the median values are calculated from global JPL GIMs. Figure 2 plots the global $\triangle$ TEC as a function of longitude and latitude at selected six universal times (02:00, 04:00, 06:00, 08:00, 12:00 and 14:00 UT) on 10 February (day 41) 2004. The corresponding median values are evaluated from the 31day global GIMs centered on 10 February 2004.

As can be seen in Fig. 2, the 10 February 2004 TEC enhancement is evidently a regional event. The constructed global $\triangle T E C$ maps show that the TEC enhanced regions are confined at the EIA crest latitudes in the Northern and Southern Hemispheres with a narrow longitudinal band centered at longitude around $120^{\circ} \mathrm{E}$. The enhancements of JPL TEC started at 04:00 UT, well-developed at 08:00 UT, and disappeared at 12:00 UT. During the well-developed EIA intervals, the enhancement is stronger in the Northern/winter Hemisphere and with a wider longitudinal band than the Southern/summer Hemisphere. Moreover, the time evolution 


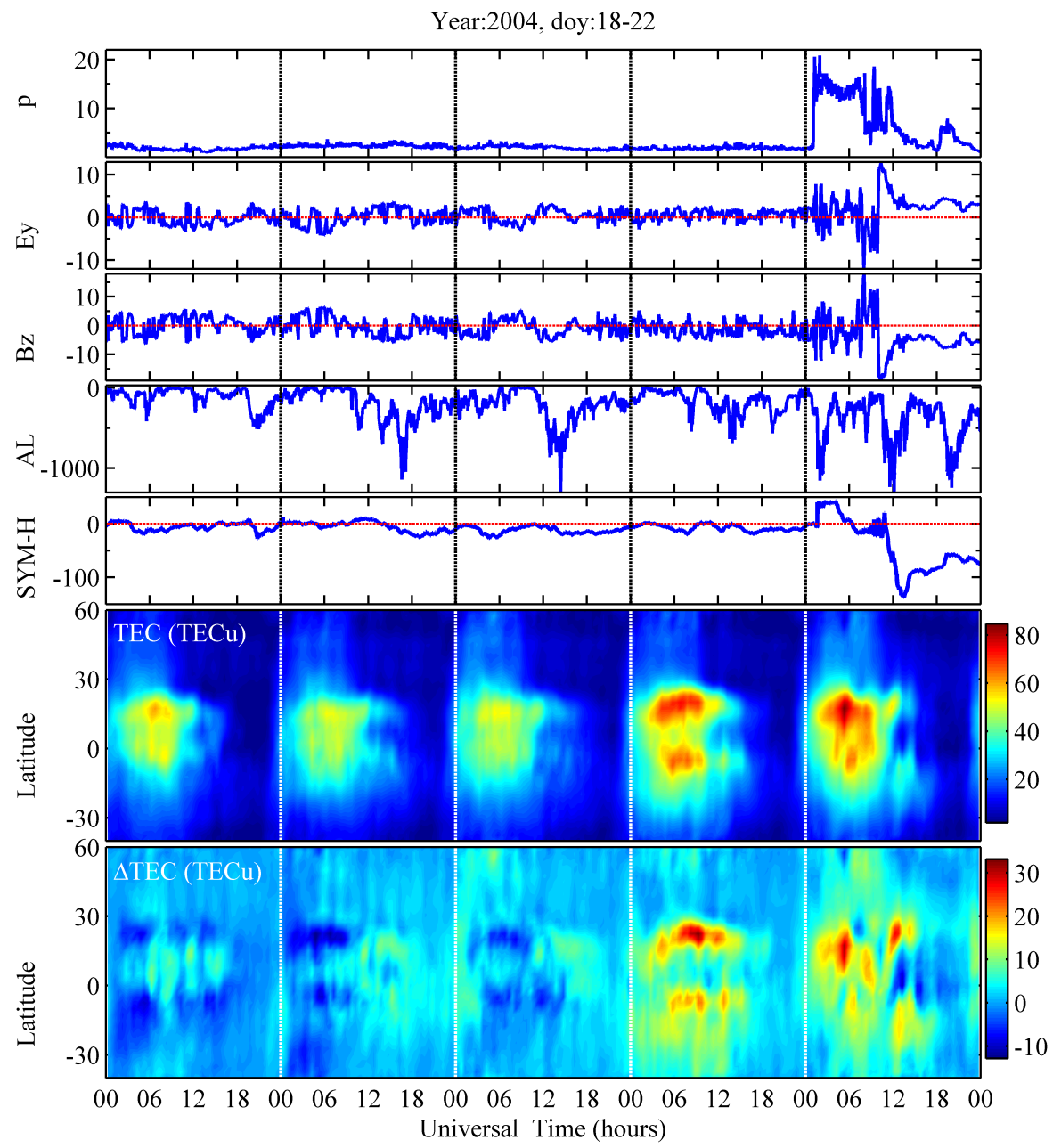

Fig. 3. Same as Fig. 1, but for 18-22 January (days 18-22) 2004. TEC were enhanced at low latitudes in both hemispheres on 21 January 2004.

and latitudinal coverage of the enhanced $\triangle$ TEC derived from JPL GIM is generally consistent with that of the regional TEC, as shown in the bottom panel of Fig. 1.

\subsection{The 21 January 2004 event}

The second enhancement event occurred on 21 January 2004, followed by a storm on 22 January 2004. Similar to Fig. 1, Fig. 3 plots the ACE satellite measured solar wind dynamic pressure $p$, IEF $E_{y}$ and IMF $B_{z}$, as well as AL and SYM-H indices on 18-22 January 2004. As demonstrated in Fig. 3, a storm started on 22 January 2004. The preceding four days (18-21 January) were geomagnetically quiet, according to SYM-H index. In contrast, it is interesting that the situation at high latitudes is dynamic; geomagnetic bursts are in progress on 19 and 20 January, as indicated by AL index. Solar winds and huge IMF disturbances were approaching the Earth at the beginning hours of 22 January, which caused a geomagnetic storm with a SSC at $1.58 \mathrm{UT}$.
The bottom two panels in Fig. 3 show values of the regional TEC and $\triangle \mathrm{TEC}$ along $120^{\circ} \mathrm{E}$ during $18-22$ January 2004. As seen from the bottom two contours in Fig. 3, the EIA is evidently more developed on 21 January 2004 with a stronger northern/winter EIA crest. Previous observations reveal that the plasma density in the F-layer is higher in winter than in summer, a feature known as a winter anomaly. During the enhancement the northern EIA crest moves to higher latitudes, compared to the preceding quiet days. The most marked enhancement of TEC appears in the local afternoon.

\subsection{The 4 March 2001 event}

A TEC enhancement event occurred on 4 March 2001, just before the onset of the 4 March 2001 storm. Similar to Figs. 1 and 3, Fig. 4 plots the ACE satellite measured solar wind dynamic pressure $p$, IEF $E_{y}$ and IMF $B_{z}$, as well as AL and SYM-H indices on 1-5 March 2001. As demonstrated in Fig. 4, a storm started on 4 March 2001 when the 


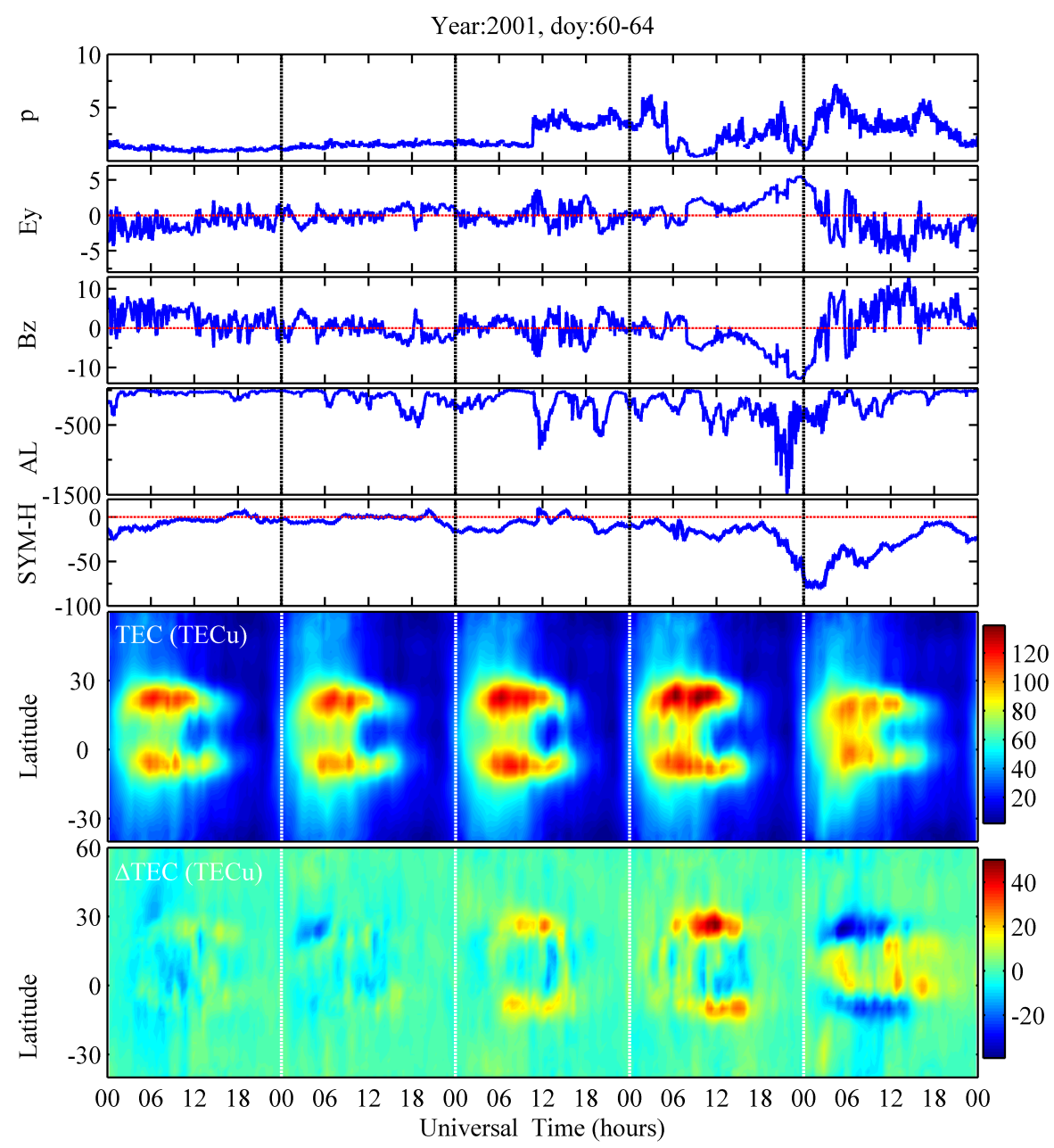

Fig. 4. Same as Fig. 1, but for 1-5 March (days 60-64) 2001. TEC were enhanced at low latitudes in both hemispheres on 4 March 2001.

enhancement event was over. A difference in this event from the above two events is that a shock wave was approaching the Earth around 12:00 UT on 3 March, as indicated by solar wind dynamic pressure $p$ (top panel of Fig. 4). As a result, it is interesting that the prestorm $\mathrm{AL}$ index is quite dynamic, although its values are not very high, while the SYM-H index is low. This is a case of the so-called HILDCAA (High Intensity, Long Duration, Continuous Auroral Activity), which appears when the Earth passes through the so-called Corotating Interaction Regions (CIR); more about this kind of phenomena can be found in Tsurutani and Gonzalez (1997).

The bottom two panels in Fig. 4 show the regional TEC and $\triangle \mathrm{TEC}$ along $120^{\circ} \mathrm{E}$ during $1-5$ March 2001 . As is evident, the EIA becomes stronger on 3 March and more significant on 4 March. The latitudes of the regional TEC enhancement are again located at the south and north EIA crests. The most marked enhancements of TEC also appear at intervals from local afternoon to evening.

Figure 5 plots the global $\triangle$ TEC constructed from JPL GIMs as a function of longitude and latitude at selected six universal times (05:00, 07:00, 09:00, 13:00, 15:00 and 19:00 UT) on 4 March 2001. The global $\triangle$ TEC maps illustrate that the unusual enhancement can be detected from JPL GIMs at intervals from 09:00 UT to 15:00 UT. The 4 March 2001 TEC enhancement is also a regional event. However, the situation of global TEC is quite different from the regional result (the bottom panel of Fig. 4). The enhancement in JPL global TEC is clustered around the northern EIA crest latitudes in a narrow longitudinal band centered at a longitude around $120^{\circ} \mathrm{E}$. An enhancement signature cannot be easily found in the Southern Hemisphere. In contrast, the enhancement in the regional TEC appears at both hemispheres, although the southern one is relatively weaker. The differences are possibly due to many more GPS receivers in the Asia/Australia sector being included in constructing the regional TEC data than the JPL GIM TEC.

Burešová and Laštovička (2008) found no systematic effect of any foF 2 prestorm enhancement in the $\mathrm{F} 1$ region, which indicates possible altitudinal dependence. To explore whether or not the signature of enhancements can be found 


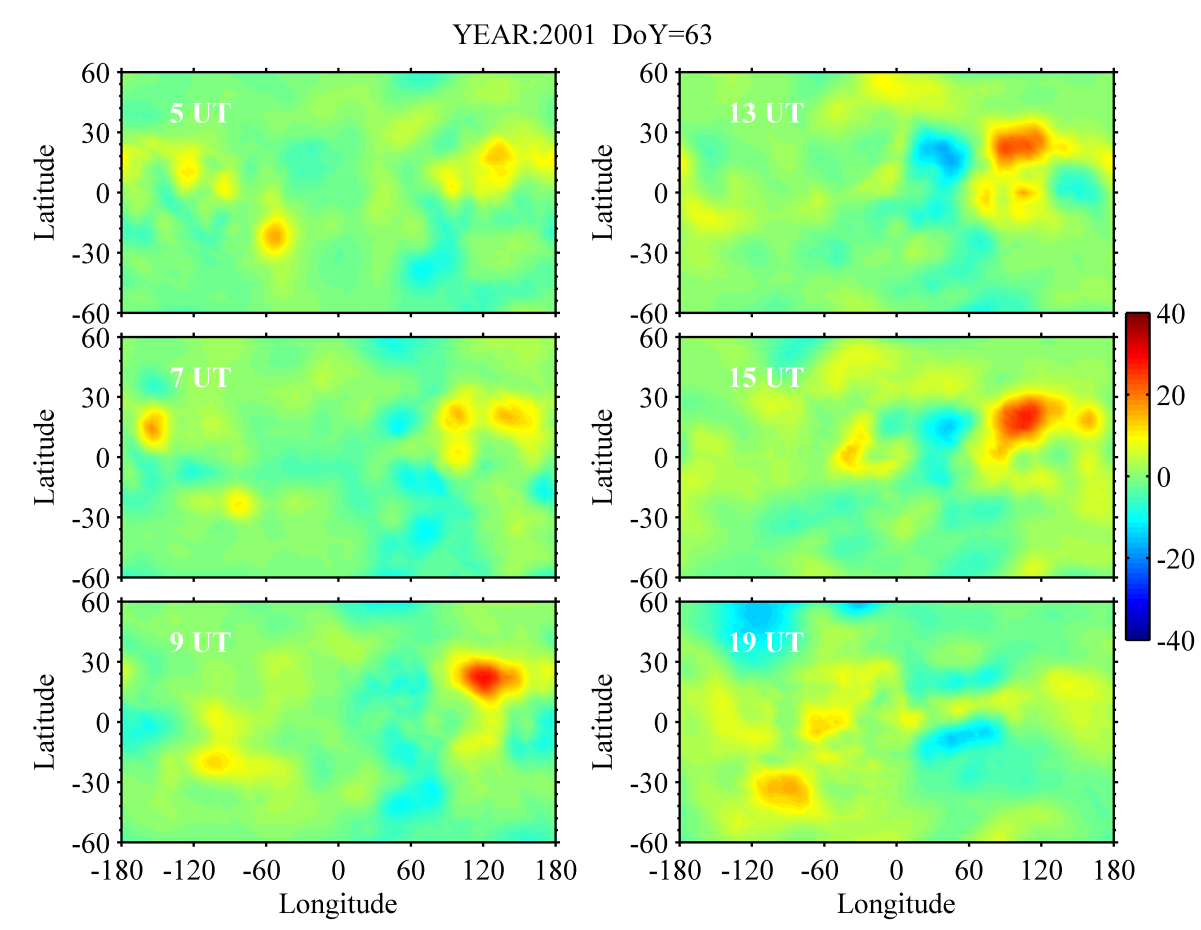

Fig. 5. Same as Fig. 2, but for the event on 4 March 2001. The median values are evaluated from the 31-day observations centered on 4 March 2001.

in the topside ionosphere, we check the DMSP F13 total ion concentrations $\left(N_{i}\right)$ observations. Fortunately, during the 4 March 2001 event DMSP F13 passed over the TEC enhancement regions which were illustrated in Figs. 4 and 5. The left panel of Fig. 6 demonstrates the trajectories of selected DMSP F13 passes on 3 March 2001 (solid curve) and 4 March 2001 (dotted curve), and the right panel for $N_{i}$ during the F13 passes shown in the left panel. Leaving aside the plasma irregularity structures $\left(N_{i}\right.$ spikes in the right panel), an obvious feature of Fig. 6 is that the values of $N_{i}$ at $840 \mathrm{~km}$ altitude in the TEC enhanced regions are considerably higher on 4 March (doy=63) than those on 3 March (doy=62). Thus, enhancement in plasma density also occurred in the topside ionosphere during this event. It also provides evidence of the existence of enhanced electric fields (Zhao et al., 2005). Another interesting feature is that the magnitude of the $N_{i}$ elevation tends to be more pronounced in the Northern Hemisphere, compared to that in the Southern Hemisphere, which is consistent with the result of our regional TEC data (Fig. 4). However, the overall level $N_{i}$ is elevated over the whole latitude range, and not just limited in the EIA crest latitudes as is the regional TEC.

\section{Discussion}

Both Burešová and Laštovička (2007) and Liu et al. (2008) demonstrated that the solar flare effects are generally not the

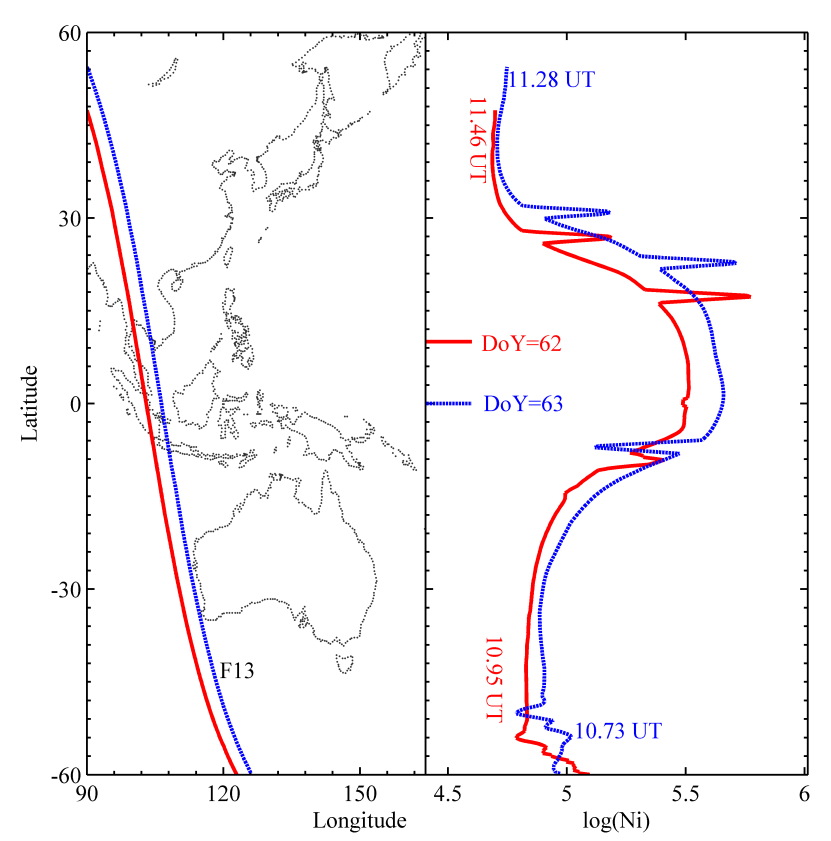

Fig. 6. (Left) Trajectories of DMSP F13 spacecraft during the 3 March (red solid trace) and 4 March (blue dotted trace) 2001 passage over the TEC enhancement region. (Right) DMSP F13 observation of plasma density in the topside ionosphere during $10.73-$ 11.28 UT on 4 March (blue dotted trace) 2001 and during 10.9511.46 UT on 3 March (red solid trace) 2001. 

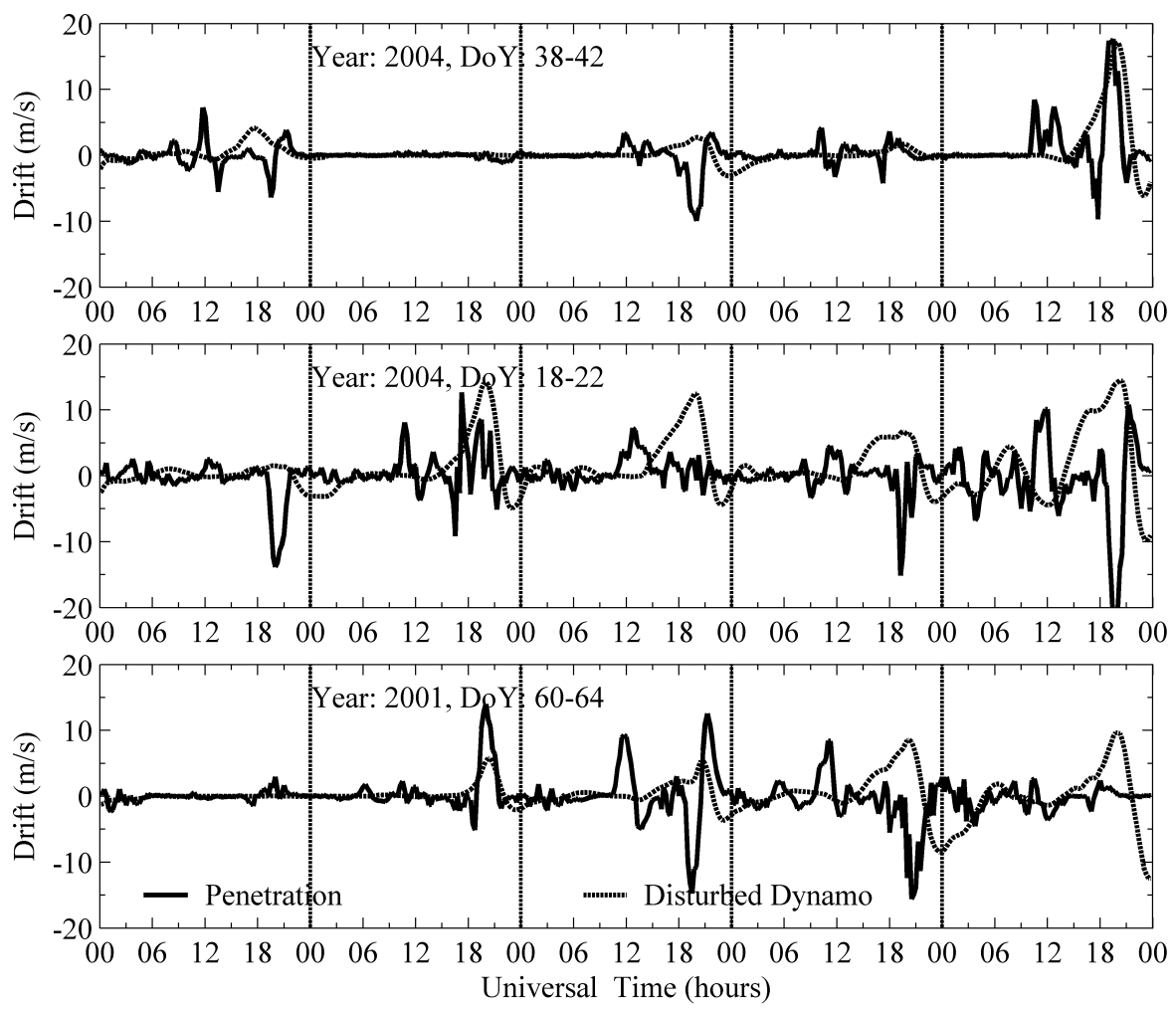

Fig. 7. The prompt penetration vertical drifts and perturbed vertical drift components due to disturbed wind circulation dynamo effects during the periods of those three events. These vertical drifts were predicted by the storm-time drift model of Fejer and Scherliess (1997).

main driver for these unusual enhancements; thus, we will no longer discuss the solar flare effects. Based on the fact that there were better developed EIA presented in those events, Liu et al. (2008) suggested that the enhanced zonal electric field or vertical plasma drift is a likely cause for low-latitude unusual enhancements.

It is well known that the equatorial electric field plays an important role in the variations of the equatorial and low latitude F2 layer ionosphere under both geomagnetically quiet and active conditions (Abdu, 1997; Fejer, 2002; Huang et al., 2006; Huba et al., 2005; Maruyama et al., 2007). Enhanced equatorial electric fields during storms have been reported (e.g. Huang et al., 2005; Lin et al., 2005; Tsurutani et al., 2004; Zhao et al., 2005), which may induce the so-called super-fountain effect in the equatorial ionosphere. Many investigations revealed that, the perturbations in the equatorial plasma drift are due to the combined effects of direct penetration and longer lasting ionospheric disturbed dynamo electric fields (Fejer, 2002; Fejer and Scherliess, 1997; Tsurutani et al., 2004). Prompt penetration electric fields occur during periods of rapid and large IMF driven changes. Thus, solar wind and magnetospheric driving mechanisms often directly affect the ionosphere at low latitude, even at middle latitudes (Huang et al., 2002, 2006). Southward turnings of IMF $B_{z}$ mark enhanced magnetospheric convection and pro- duce a dawn-dusk electric field in the equatorial ionosphere. The y-component of the solar wind electric field can be directly mapped to the equatorial ionosphere, giving rise to a penetration electric field and a vertical drift (Kelley et al., 2003). The penetration drifts have typical lifetimes of about an hour.

Another kind of disturbed electric field is associated with storm-time thermospheric circulation, driven by enhanced energy deposition into the high-latitude ionosphere (e.g. Abdu, 1997). According to the results of empirical and theoretical models, the ionospheric disturbance dynamo electric fields at low latitude are westward by daytime and eastward at night, with longer time delays of about 20-30 h (Scherliess and Fejer, 1997).

Figure 7 plots the components of prompt penetration and perturbed dynamo vertical drifts, as predicted by the stormtime drift model of Fejer and Scherliess (1997) using observed AE indices during these events. The solid curves present the prompt penetration component, while the dashed lines present the perturbed dynamo vertical drifts. It should be mentioned that the model of Fejer and Scherliess (1997) cannot always predict the actual situation quite well. Several studies have shown large discrepancies in vertical drifts between observations and that of Fejer and Scherliess' model (see, e.g. Liu et al., 2002) in some situations. 
Strong electron density enhancements are frequently observed during geomagnetic storms (Kelley et al., 2003; Kutiev et al., 2006, 2007; Lin et al., 2005; Liu et al., 2004). Kutiev et al. $(2006,2007)$ observed strong TEC enhancements at the end of the recovery phase of geomagnetic storms. Since the ionospheric disturbances caused by geomagnetic activities usually last 1-3 days, Kutiev et al. $(2006,2007)$ attributed the enhancements of TEC during some events to the "post storm effects". Although SYM-H indices are low during these events (see Figs. 1, 3, and 5), continuous heating of the auroral thermosphere by electrojet current and particle precipitations are possible when geomagnetic activity in the high latitude ionosphere is active. Both AL indices and the predicted vertical drifts (Fig. 7) show that the atmosphere is disturbed 6 to $8 \mathrm{~h}$ ahead of TEC enhancing on 10 February 2004. For the 21 January 2004 and 4 March 2001 events, the predicted vertical drifts (Fig. 7) are disturbed in the preceding two days as well as during the enhancement periods.

Global maps of TEC deviations during the selected events (Figs. 2 and 5) clearly show that enhanced TEC structures are confined around $120^{\circ} \mathrm{E}$ longitude. It is interesting to note that some events of enhanced TEC during storms were reported to be confined in regions in the literature (for example, Kelley et al., 2004). This kind of enhancement was called a storm-enhanced density (SED), which is regularly observed in the pre-midnight sub-auroral ionosphere (Kelley et al., 2004). Probably, the TEC enhancement in the equatorial anomaly crests is strongly local-time dependent, which deserves further investigation.

In contrast, there are also events (e.g. the 6 January 1998 event) with quasi-periodic TEC enhancements not related to geomagnetic activity and associated probably with planetary wave type oscillations. Planetary wave effects in the F2-layer have been reported previously (e.g. Altadill and Apostolov, 2003; Xiong et al., 2006). Although planetary waves cannot propagate directly upwards to the altitude of the F-layer, due to the viscosity effects, they can affect the F-region processes via modulating ionospheric E-layer dynamo electric fields and mapping to higher altitudes along geomagnetic field lines. This extremely large day-to-day variability under such a long period of low geomagnetic activity suggests that this kind of enhancement event should not be caused by the effects of auroral activities/ magnetospheric origins, rather possibly by the atmospheric origin.

However, at present, we have difficulties in separating sources associated with auroral/magnetospheric activities from those in the atmosphere itself or from below. The historical state of geomagnetic activity makes the question more complicated. To say the least, if the low-latitude enhancements can be attributed to enhanced zonal electric fields or vertical plasma drifts, the latitudinal extent of positive $\triangle T E C$ can be explained. However, we still have difficulty to answer why these unusual TEC enhancements only appear in the narrow longitudinal band.

\section{Summary}

To reveal the behaviors of unusual ionospheric enhancements at low latitudes during low magnetic activity before the storms, we analyzed selected low-latitude enhancement events by using TEC measurements from regional and global GPS receivers. The main results of this investigation may be listed as follows:

Strong low-latitude enhancements under a long period of low geomagnetic activity before the storms are simultaneously presented in regional TEC and JPL GIMs. These enhancements are regional events, having longitudinal and latitudinal extent. The regions of TEC enhancements are confined at narrow longitude ranges with centers at around longitude $120^{\circ} \mathrm{E}$. The latitudinal belts of the maxima of enhancements located around the northern and southern EIA crests, are consistent with those events presented by Liu et al. (2008). Besides, both data sources show general similar features during these events; differences are also presented, possibly due to many more GPS receivers being included in constructing the regional TEC maps in the Asia/Australia sector.

The 10 February 2004, 21 January 2004, and 4 March 2001 events are possibly the effects associated with auro$\mathrm{ral} /$ magnetospheric activities, according to the conditions of solar wind, interplanetary electric and magnetic fields observed by ACE satellite, as well as AL and SYM-H indices. There are also quasi-periodic enhancement events (e.g. the 6 January 1998 event, figure not shown here), not related to geomagnetic activity and associated probably with planetary wave type oscillations. However, we still have difficulties in separating the possible sources. More coordinate observations are requested to identify the contributions from different sources.

Acknowledgements. The authors thank two referees for valuable suggestions. The SYM-H and AL indices are downloaded from http://swdcwww.kugi.kyoto-u.ac.jp/. Ionospheric data are provided from http://cddisa.gsfc.nasa.gov/. The ACE solar wind data are provided by CEDAR Data System from the Principal Investigator D. J. McComas of Southwest Research Institute. The DMSP data are provided by the Center for Space Sciences at University of Texas at Dallas and the US Air Force. The code for the empirical model for storm time equatorial zonal electric fields was kindly provided by L. Scherliess. This research was supported by National Natural Science Foundation of China (40725014, 40674090, 40134020) and National Important Basic Research Project (2006CB806306).

Topical Editor M. Pinnock thanks J. Laštovičká and I. Kutiev for their help in evaluating this paper. 


\section{References}

Abdu, M. A.: Major phenomena of the equatorial ionosphere under disturbed conditions, J. Atmos. Sol.-Terr. Phy., 59, 1505-1519, 1997.

Altadill, D. and Apostolov, E. M.: Time and scale size of planetary wave signatures in the ionospheric $\mathrm{F}$ region: Role of the geomagnetic activity and mesosphere/lower thermosphere winds, J. Geophys. Res., 108(A11), 1403, doi:10.1029/2003JA010015, 2003.

Araujo-Pradere, E. A., Fuller-Rowell, T. J., and Bilitza, D.: Time Empirical Ionospheric Correction Model (STORM) response in IRI2000 and challenges for empirical modeling in the future, Radio Sci., 39(1), RS1S24, doi:10.1029/2002RS002805, 2004.

Blagoveshchensky, D. V., MacDougall, J. W., and Piatkova, A. V.: Ionospheric effects preceding the October 2003 Halloween storm, J. Atmos. Sol.-Terr. Phy., 68, 821-831, 2006.

Buonsanto, M. J.: Ionospheric storms - a review, Space Sci. Rev., 88, 563-601, 1999.

Burešová, D. and Laštovička, J.: Pre-storm enhancements of $f_{o} \mathrm{~F} 2$ above Europe, Adv. Space Res., 39(8), 1298-1303, 2007.

Burešová, D. and Laštovička, J.: Pre-storm electron density enhancements at middle latitudes, J. Atmos. Sol.-Terr. Phy., 70, doi:10.1016/j.jastp.2008.01.014, in press, 2008.

Danilov, A. D.: F2-region response to geomagnetic disturbances, J. Atmos.-Sol. Terr. Phy., 63, 441-449, 2001.

Fejer, B. G.: Low latitude ionospheric electrodynamics, J. Atmos.Sol. Terr. Phy., 64, 1401-1408, 2002.

Fejer, B. G. and Scherliess, L.: Empirical models of storm time equatorial zonal electric fields, J. Geophys.Res., 102(A11), 24 047-24 056, 1997.

Forbes, J. M., Palo, S. E., and Zhang, X. L.: Variability of the ionosphere, J. Atmos.-Sol. Terr. Phy., 62(8), 685-693, 2000.

Huang, C.-S., Foster, J. C., and Erickson, P. J.: Effects of solar wind variations on the midlatitude ionosphere, J. Geophy. Res., 107(A8), 1192, doi:10.1029/2001JA009025, 2002.

Huang, C.-S., Foster, J. C., and Kelley, M. C.: Long-duration penetration of the interplanetary electric field to the low-latitude ionosphere during the main phase of magnetic storms, J. Geophys. Res., 110, A11309, doi:10.1029/2005JA011202, 2005.

Huang, C., Sazykin, S., Spiro, R., Goldstein, J., Crowley, G., and Ruohoniemi, J. M.: Storm-Time Penetration Electric Fields and Their Effects, Eos Trans. AGU, 87(13), 131, doi:10.1029/2006EO130005, 2006.

Huba, J. D., Joyce, G., Sazykin, S., Wolf, R., and Spiro, R.: Simulation study of penetration electric field effects on the lowto mid-latitude ionosphere, Geophys. Res. Lett., 32, L23101, doi:10.1029/2005GL024162, 2005.

Iijima, B. A., Harris, I. L., Ho, C. M., Lindqwister, U. J., Mannucci, A. J., Pi, X., Reyes, M. J., Sparks, L. C., and Wilson, B. D.: Automated daily process for global ionospheric total electron content maps and satellite ocean altimeter ionospheric calibration based on Global Positioning System data, J. Atmos. Sol.-Terr. Phy., 61, 1205-1218, 1999.

Iyemori, T. and Rao, D. R.: Decay of the $D_{s t}$ field of geomagnetic disturbance after substorm onset and its implication to stormsubstorm relation, Ann. Geophys., 14, 608-618, 1996, http://www.ann-geophys.net/14/608/1996/.

Kane, R. P.: Global evolution of F2-region storms, J. Atmos. Terr. Phys., 35, 1953-1966, 1973.
Kane, R. P.: Ionospheric $f o F 2$ anomalies during some intense geomagnetic storms, Ann. Geophs., 23, 2487-2499, 2005.

Kelley, M. C., Makela, J. J., Chau, J. L., and Nicolls, M. J.: Penetration of the solar wind electric field into the magnetosphere/ionosphere system, Geophys. Res. Lett., 30(4), 1158 , doi:10.1029/2002GL016321, 2003.

Kelley, M. C., Vlasov, M. N., Foster J. C., and Coster, A. J.: A quantitative explanation for the phenomenon known as storm-enhanced density, Geophys. Res. Lett., 31, L19809, doi:10.1029/2004GL020875, 2004.

Kutiev, I. and Muhtarov, P.: Modeling of midlatitude $F$ region response to geomagnetic activity, J. Geophys. Res., 106(A8), 15 501-15 509, 2001.

Kutiev, I., Otsuka, Y., Saito, A., and Watanabe, S.: GPS observations of post-storm TEC enhancements at low latitudes, Earth Planets Space, 58, 1479-1486, 2006.

Kutiev, I., Otsuka, Y., Saito, A., and Watanabe, S.: Low-latitude total electron content enhancement at low geomagnetic activity observed over Japan, J. Geophys. Res., 112, A07306, doi:10.1029/2007JA012385, 2007.

Laštovička, J.: Forcing of the ionosphere by waves from below, J. Atmos. Sol.-Terr. Phy., 68, 479-497, 2006.

Laštovička, J. and Šauli, P.: Are planetary wave type oscillations in the $\mathrm{F} 2$ region caused by planetary wave modulation of upward propagating tides?, Adv. Space Res., 24(11), 1473-1476, 1999.

Lin, C. H., Richmond, A. D., Liu, J. Y., Yeh, H. C., Paxton, L. J., Lu, G., Tsai, H. F., and Su, S.-Y.: Large-scale variations of the low-latitude ionosphere during the October-November 2003 superstorm: Observational results, J. Geophys. Res., 110, A09S28 doi:10.1029/2004JA010900, 2005.

Liu, L., Wan, W., Ning, B., Yuan, H., and Liu, J.: Low latitude ionospheric effects near longitude $120^{\circ} \mathrm{E}$ during the great geomagnetic storm of July 2000, Science in China (A), 45 (Supp.), 148-155, 2002.

Liu, L., Wan, W., Lee, C. C., Ning, B., and Liu, J. Y.: The low latitude ionospheric effects of the April 2000 magnetic storm near $120^{\circ}$ E, Earth Planet Space, 56, 607-612, 2004.

Liu, L., Wan, W., Zhang, M.-L., Zhao, B., and Ning, B.: Prestorm enhancements in $N m \mathrm{~F} 2$ and TEC at low latitudes, J. Geophys. Res., 113, A02311, doi:10.1029/2007JA012832, 2008.

Mannucci, A. J., Wilson, B. D., Yuan, D. N., Ho, C. M., Lindqwister, U. J., and Runge, T. F.: A global mapping technique for GPSderived ionospheric total electron content measurements, Radio Sci., 33, 565-582, 1998.

Maruyama, N., Sazykin, S. Spiro, R. W., Anderson, D., et al.: Modeling storm-time electrodynamics of the low-latitude ionosphere-thermosphere system: Can long lasting disturbance electric fields be accounted for?, J. Atmos. Sol.-Terr. Phy., 69(10-11), 1182-1199, 2007.

Mendillo, M.: Storms in the ionosphere: Patterns and processes for total electron content, Rev. Geophys., 44, RG4001, doi:10.1029/2005RG000193, 2006.

Mikhailov, A. V., Depueva, A. Kh., and Yu. Leschinskaya, T.: Morphology of quiet time F2-layer disturbances: High and lower latitudes, Int. J. Geomagn. Aero., 5, GI006, doi:10.1029/2003GI000058, 2004.

Mikhailov, A. V., Depueva, A. H., and Depuev, V. H.: Daytime F2layer negative storm effect: what is the difference between storminduced and Q-disturbance events?, Ann. Geophs., 25, 1531- 
1541, 2007a.

Mikhailov, A. V., Depuev, V. H., and Depueva, A. H.: Synchronous $\mathrm{NmF} 2$ and $\mathrm{NmE}$ daytime variations as a key to the mechanism of quiet-time F2-layer disturbances, Ann. Geophs., 25, 483-493, $2007 b$.

Prölss, G. W.: Ionospheric F-region storms, in: Handbook of atmospheric electrodynamics, edited by: Volland, H., CRC Press, 195-247, 1995.

Scherliess, L. and Fejer, B. G.: Storm time dependence of equatorial disturbance dynamo zonal electric fields, J. Geophys. Res., 102(A11), 24 037-24 046, 1997.

Tsurutani, B., Mannucci, A., Iijima, B., et al.: Global dayside ionospheric uplift and enhancement associated with interplanetary electric fields, J. Geophys. Res., 109, A08302, doi:10.1029/2003JA010342, 2004.
Tsurutani, B. T. and Gonzalez, W. D.: The interplanetary causes of magnetic storms: A review, in: Magnetic Storms, Geophys. Monogr. Ser., vol. 98, edited by: Tsurutani, B. T., Gonzalez, W. D., Kamide, Y., and Arballo, J. K., pp. 77-89, AGU, Washington, D.C., 1997.

Xiong, J., Wan, W., Ning, B., Liu, L., and Gao, Y.: Planetary wave-type oscillations in the ionosphere and their relationship to mesospheric/lower thermospheric and geomagnetic disturbances at Wuhan (30.61 N, 114.51 E), J. Atmos. Sol.-Terr. Phy., 68, 498508, 2006.

Zhao, B., Wan, W., and Liu, L.: Responses of equatorial anomaly to the October-November 2003 superstorms, Ann. Geophys., 23, 693-706, 2005,

http://www.ann-geophys.net/23/693/2005/. 